\title{
Holistic Analysis of Cytokine and Cytokine Storm Researches in Scientific Literature: A Bibliometric Study of the Global Publications between 1980 and 2018
}

\author{
Mustafa Şahin $^{1}$ and Engin Şenel ${ }^{2}$ \\ ${ }^{1}$ Hitit University Erol Olçok Training and Research Hospital \\ ${ }^{2}$ Hitit University Faculty of Medicine
}

December 23, 2020

\begin{abstract}
Aim: Bibliometrics has been used for assessing and predicting trends in macro-health science and medical systems, especially in the field of cancer. Bibliometric and scientometric studies in the field of cytokines may guide further research in this field. Cytokines in particular cytokine storm has recently started to be highly discussed and studied in global viral infections. In the SARS-CoV-2 pandemic, cytokine storm was seen in many patients. In this study we want to present to perform bibliometric analysis of articles on cytokine and cytokine storm published in the academic literature during 1980 to 2018. Methods: The bibliometric analysis was performed using the Thomson Reuters Web of Science database. Results: A total of 232,606 articles were retrieved, $82.52 \%$ of which were original articles. The United States was the leading country by total publication number $(\mathrm{n}=84,426,36.29 \%)$, followed by Japan $(\mathrm{n}=21,983,9.45 \%)$ produced the most literature on cytokine. Among the institutions identified, Harvard University (USA) contributed the most articles on cytokine. All authors and institutions in the top 10 contributor's lists were from the developed countries. Conclusions: Researchers from the developing and least-developed countries should be encouraged to perform novel studies on cytokine. Cytokine studies are associated with the pathology and physiological variability of many diseases and may have beneficial results in the medical field. Cytokine and cytokine storm studies may be particularly useful in identifying the pathogenesis of global viral infections such as SARS-CoV-2, evaluating and developing new treatment strategies.
\end{abstract}

\section{Hosted file}

Manuscript.pdf available at https://authorea.com/users/369070/articles/500164-holisticanalysis-of-cytokine-and-cytokine-storm-researches-in-scientific-literature-a-

bibliometric-study-of-the-global-publications-between-1980-and-2018 

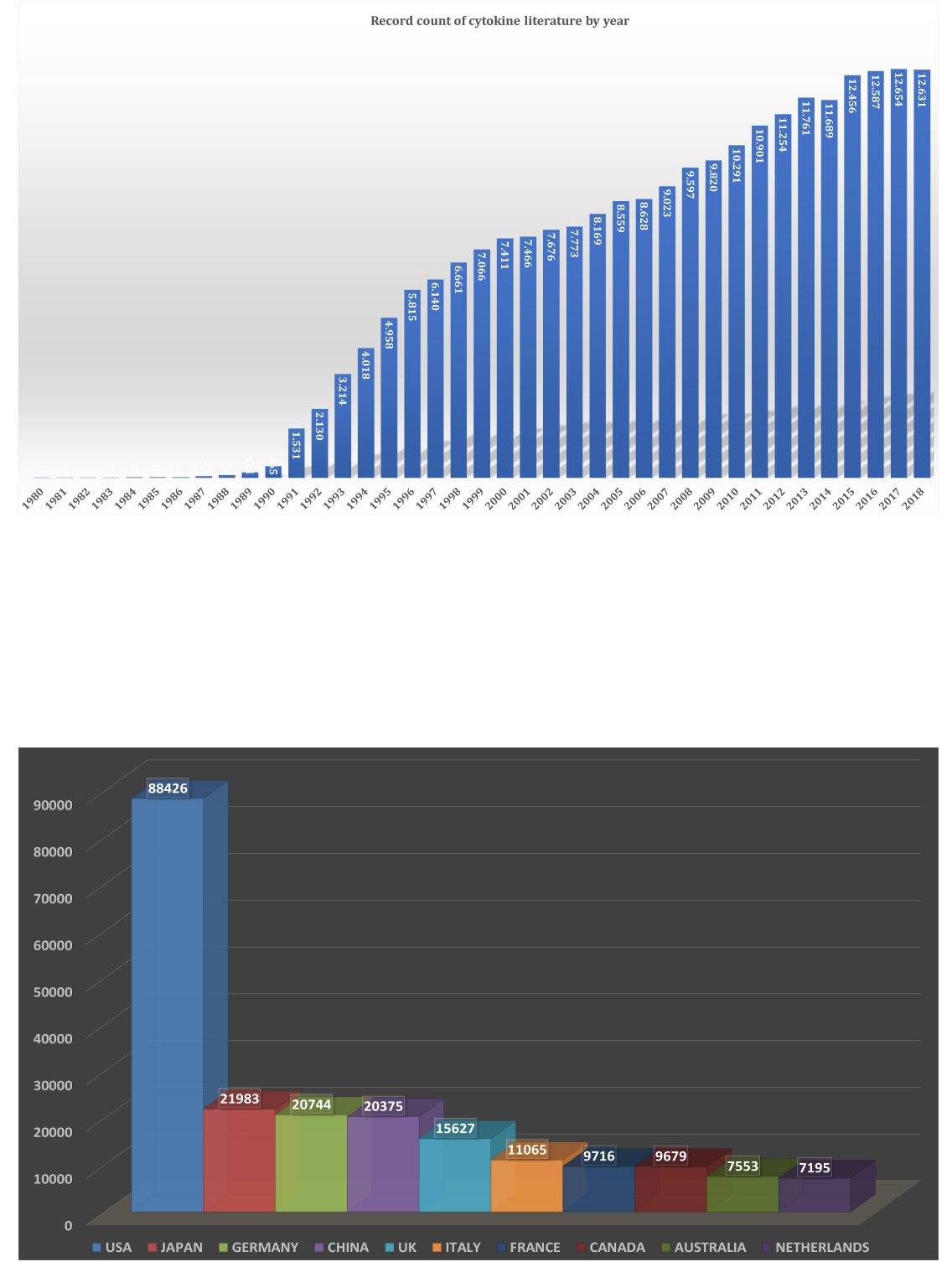

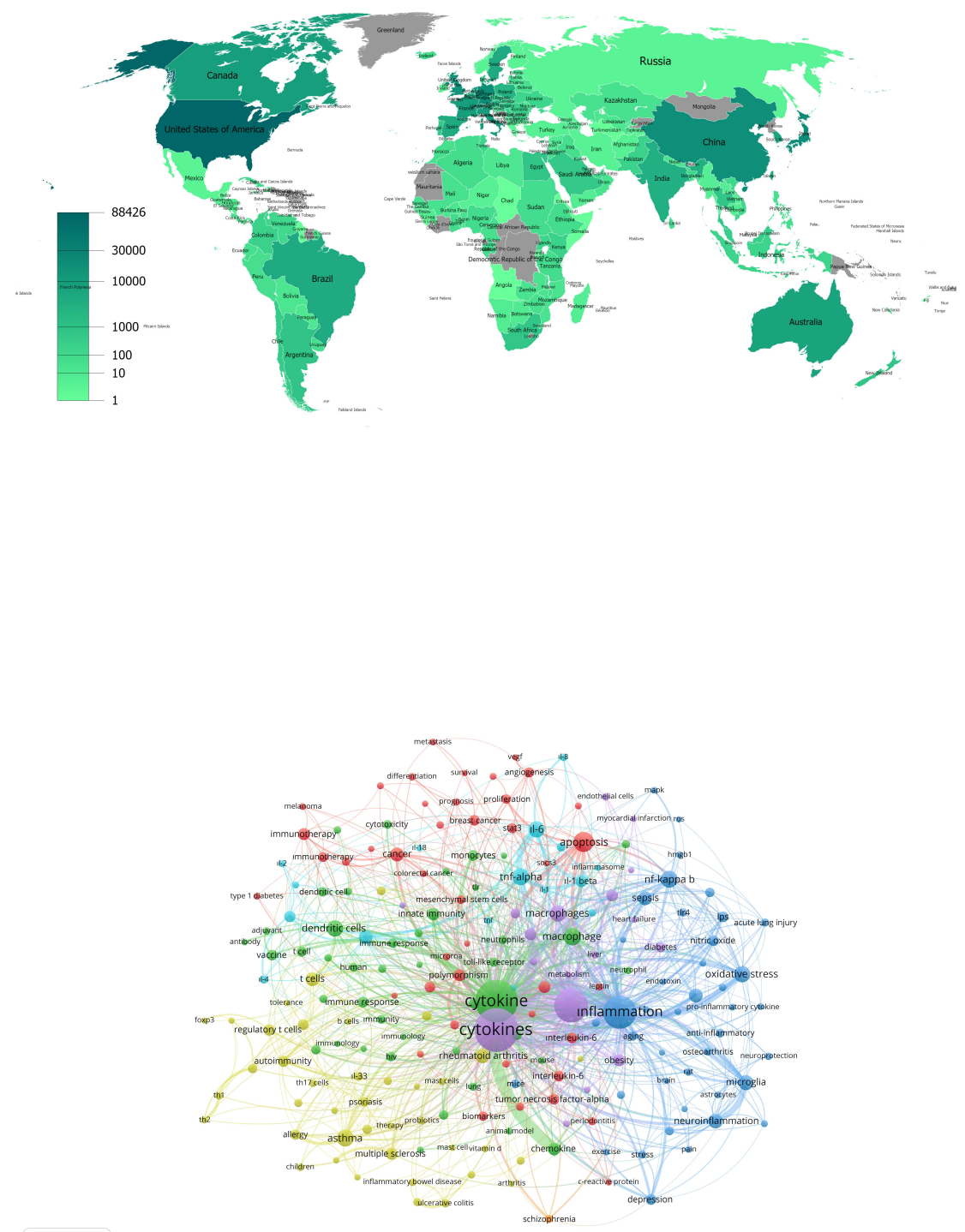

\& vosviewer 


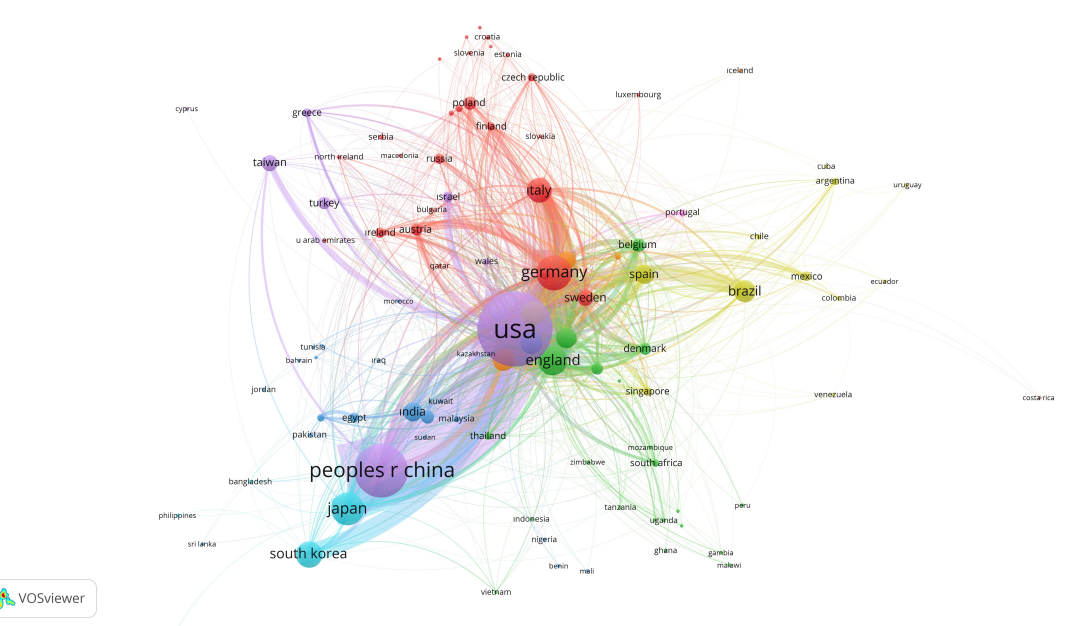

A vosviewer

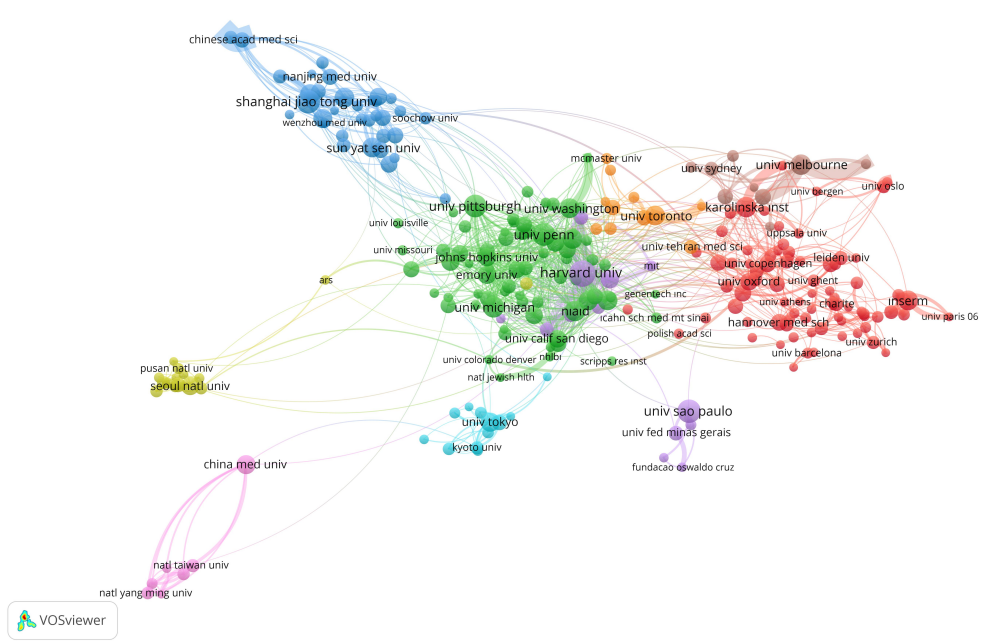

\section{Hosted file}

Figure 7.pdf available at https://authorea.com/users/369070/articles/500164-holisticanalysis-of-cytokine-and-cytokine-storm-researches-in-scientific-literature-abibliometric-study-of-the-global-publications-between-1980-and-2018

\section{Hosted file}

Tables.pdf available at https://authorea.com/users/369070/articles/500164-holistic-analysisof-cytokine-and-cytokine-storm-researches-in-scientific-literature-a-bibliometric-studyof-the-global-publications-between-1980-and-2018 